\title{
Flying Carpets and Urban Development Trajectories
}

\author{
Piet Rietveld
}

Received: 5 May 2014 / Accepted: 5 March 2015 /

Published online: 2 June 2015

(C) The Author(s) 2015. This article is published with open access at Springerlink.com

\begin{abstract}
Generalised costs of transport and communication have decreased in many domains during the past centuries. Some cities have strongly benefitted from these developments. The more recent development is that passenger transport has become the leading driving force, as opposed to freight transport in earlier logistical revolutions. Information and Communication Technology (ICT) is a substitute for some forms of physical transport but certainly not for all; cities continue to depend on high quality transport networks. An underestimated component of transport networks is vertical transport in high rise buildings. This played a key role in urban developments in the 20th century and it may be expected to continue its role in the next century. Probably, the 'flying carpet' notion is most clearly visible in the vertical movements in high-rise buildings.
\end{abstract}

Keywords Flying carpet - Logistics · Agglomeration advantages · Vertical transport · Accessibility

\section{Introduction}

From the very beginning transport has been one of the key factors underlying urban growth and development. Leading cities in world history such as Rome, Venice, London and New York owe their success in a considerable degree to technical and logistic innovations in the transport domain. As we will discuss, there is a close relationship between the dynamics of transport and logistics on the one hand and the dynamics of cities, on the other.

The key question to be addressed in this article is to what extent the ongoing process of improvement of transport and communications will lead to the further growth of cities, or whether just the opposite may be expected to occur. For example, Clark (1958) wrote an article with the title 'Transport: maker and breaker of cities', suggesting that transport may also have very adverse effects on cities. A similar claim is

Piet Rietveld deceased on November, 1, 2013, at the age of 60 years.

P. Rietveld $(\bowtie)$

Department of Spatial Economics, VU University Amsterdam, Amsterdam, Netherlands

e-mail: k.kourtit@vu.nl 
sometimes made for improvements in transport technology, for instance, applications of advanced information and telecommunication technology (ICT) such as the internet and social media.

We will show that developments in transport and communication have indeed led to turbulent developments of cities, but in most cases the cities have continued to grow, although the relative positions of cities may have changed. During the last decades we have observed an ongoing decrease in transport costs (in particular, for long run travel) and the emergence of modern telecommunication and the internet. This may be interpreted as a 'flying carpet' phenomenon: movements can take place smoothly and at low costs, giving more freedom to citizens and firms to choose where they like to go. In this paper we will discuss how cities will be affected by this development.

This paper is organized as follows. Network developments and urban development trajectorieswill address network developments and urban development from a long term perspective. Inter-urban transport and urban development; a history of logistical revolutions brings the two domains together by looking at the joint development of transport technology and cities. Internal transport within cities and urban development addresses the implications of intra-urban transport for urban development. Agglomeration advantages, transport and communications will discuss, in more detail, the key concept of agglomeration advantages and to what extent it relates to costs of transport and communication. Agglomeration advantages and transport networks gives a more detailed account of which specific transport networks are important for the realisation of agglomeration advantages. Special attention is given to vertical transport in high-rise buildings, an underdeveloped element in the analysis of urban development. Conclusion concludes.

\section{Network Developments and Urban Development Trajectories}

Transport and communication networks during the past centuries have gone through substantial cycles. A nice illustration can be found in Levinson (2005) for the USA. The 19 and 20th century have witnessed the growth and decline of at least three major networks: canals, rail and telegraph. Given the high costs of investments it sometimes took 50 years or more to build such networks, but after consolidation these networks soon started to shrink, apparently because emerging competing networks were generating high benefits.

Gruebler and Nakicenovic (1991) have undertaken a similar analysis for a broader range of countries and found that this typical inverted U-shaped pattern of development not only applies to network length, but also the network use. The effective use of canals is incredibly smaller than it was 150 years ago, and the telegraph system has vanished. The decline of rail is not as drastic as with canals and telegraph, but there has been a huge decline. Only recently the construction of high speed- and light rail has led to a renaissance of rail in a limited number of countries.

The above figure gives an important but one-sided image of long term trends in transport. Another story is told by Table 1 based on Crafts and Venables 
Table 1 Real costs of maritime transport $(1910=100)$

\begin{tabular}{llll}
\hline Year & Cost index & Year & Cost index \\
\hline 1750 & 298 & 1910 & 100 \\
1790 & 376 & 1930 & 107 \\
1830 & 287 & 1960 & 47 \\
1870 & 196 & 1990 & 51 \\
\hline
\end{tabular}

Sources: Crafts and Venables 2001; Dollar 2001; Harley 1988; Isserlis 1938

(2001), which shows that in other domains continuity tended to prevail. The table shows that for maritime transport real costs decreased with about $83 \%$ between 1770 and 1990. Impressive efficiency improvements took place in particular during the period that the steamships entered the arena (between 1870 and 1910), but also in most other periods.

As mentioned before, the key issue to be addressed in this paper is to what extent these long term cycles and trends express themselves in urban development trajectories. Do we see definite patterns where cities continue to grow, or may the opposite occur? The overall pattern for urban growth we find in the literature is represented in Fig. 2. Growth takes place in various stages, alternated with periods of decline, but in most cases the rather drastic lifecycle pattern shown for specific transport networks in Fig. 1 does not apply. The future development is uncertain, and hence at some stage a bifurcation may emerge.

The periods of upturn and downswing of cities usually have to do with lifecycles of sectors where sectors that were vital during one stage of development turned into decline, leading to deterioration in the cities that specialized in this sector. There may well be cases where this leads to the collapse of the city (think of ghost towns, rapidly developed after the finding of a natural resource, and also rapidly left after the depletion of the resource), but as indicated in Brown (1974), this mechanism will no longer work when urban size has reached higher levels (he mentions a number of 250,000 inhabitants). In that case various mechanisms (industrial diversification, invested social overhead capital, political power associated with larger cities) will stabilize the development of cities, leading to a so-called urban size ratchet providing a stabilizing force and reducing downward tendencies.

Within the context of the present paper it is relevant to find out to what extent transport conditions - in particular, new developments in transport technologyhad a specific effect on the growth or decline of specific cities. It appears that some cities with a strong transport based position in the past like London, Amsterdam, and Venice continued to keep important positions in the urban networks of Europe, although their economic orientation may have shifted far away from transport. On the other hand, there is a good number of towns that were important hubs in the past (specific port cities in the Roman empire, and a good number of Hanseatic towns) that nowadays are just insignificant spots on the maps due to physical phenomena, such as, silting up of water connections and because of shifts in trade flows. 


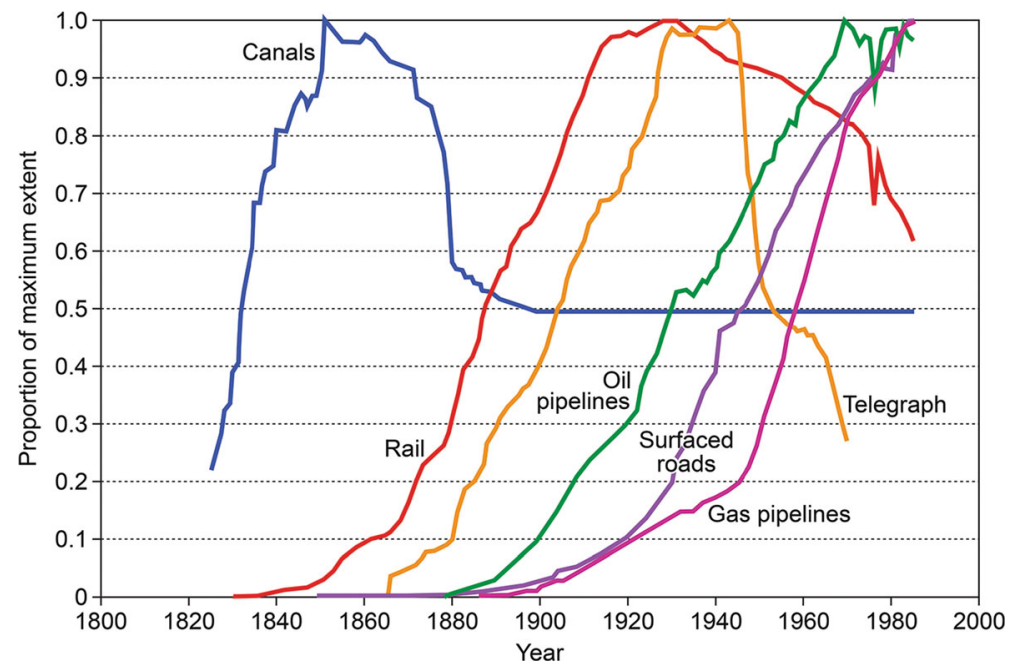

Fig 1 U.S. Networks as a proportion of maximum extent (source: Levinson 2005)

Another line of research on urban growth trajectories strongly supporting the ratchet notion has been developed by Davis and Weinstein (2002). They find for Japan that when cities receive a shock such as intensive bombings in the second world war, cities quickly return to their original position in the urban hierarchy. In a similar fashion Brakman et al. (2004) find that bombings of German cities during the second world war did not substantially change the positions of cities in the German urban hierarchy. This underlines that stochastic shocks in urban systems do not necessarily affect longer run growth rates of cities. This does not mean, of course, that all cities grow at the same rate, but it demonstrates that urban growth is not just a random walk; the locational fundamentals of a city appear to have a long term effect. At the same time the specific sectoral compostion of cities will have its effect. For example, Cheshire (1990) shows that port cities in Europe performed badly in terms of employment, most probably since during the 1970s and 1980s containerization reduced the labour intensity of freight transport. More recently economic growth in port cities is no longer smaller than that of other cities (Koks 2012). Thus, port cities experienced a dip during several decades but seem to have coped effectively with the challenges of the container revolution.

We conclude that where in specific transport networks there have been clear upswings and downswings during the past centuries, downswings in urban developments have not been as dramatic. When cities grow beyond a certain level, the ratchet mechanism tends to work as a stabilizer preventing strong downturns in cities. So, cities that depended on a strong transport function in the past and that lost this position for some reason may still be vital when they succeed in shifting their economic orientation. Meanwhile, it is clear that depending on several factors such as the sectoral composition of a city and the overall demographic developments in a country, cities will grow at varying rates. The next section gives a more in depth account of the role of transport during the various phases of economic development. 


\section{Inter-Urban Transport and Urban Development; a History of Logistical Revolutions ${ }^{1}$}

During the past millennium, four major periods of rapid and fundamental changes in the infrastructure system took place that had major impacts on the development of the urban system. Andersson (1986) described them as four logistical revolutions. He states that the great structural changes of production, location, trade, culture and institutions are triggered by slow but steady changes in the logistical network. For an update see Karlsson et al. (2009).

The first logistical revolution took place between 1000 and 1500 was based on improvements in particular in sea transportation on the one hand and the creation of a basic infrastructure for trade on the other hand. The development of larger vessels, new sea routes and new ports helped to integrate trade between city states along the coast of the Mediterranean and the Hanseatic cities along the coasts of Northern Europe. The emerging city system formed the basis for this increased trade. Owing to larger vessels, transport costs and trade barriers were reduced. Large economic trade centers in this period were Venice, Florence, Bruges, and Lubeck. The population size of those cities grew until around 100,000 inhabitants. Keywords of this era are emergence of cities, merchants, and specialization of production.

The second logistical revolution (1500-1800) was again based on maritime transport and on institutional innovations. The Portuguese and later the Dutch were able to build ocean-crossing merchant ships, while an efficient banking and credit system was developed. Both transport costs and trade barriers were further reduced by those developments. Initially, Antwerp, and somewhat later Amsterdam, were the central nodes, but all the large capital cities in Europe were engaged in international trade (Braudel 1994). By the end of this era, London became the commercial and financial centre of the world (Karlsson et al. 2009). London had about 800,000 inhabitants at that time. Keywords of this era are international trade, central banking system, science, and arts.

The third logistical revolution (1800-2000) is linked to the industrial revolution. Driven by technological innovations, the infrastructure network expanded from sea transport towards land transport; first canals and later on rail, and finally road (see Fig. 1). The new and relatively large scale transportation systems made it possible to establish vertical integration between the raw materials in Northern America and the large scale manufacturing industries in the port cities of Western Europe. Division of labor, the onset of motorization and mechanization, mass production, standardized products, and multinational companies were keywords of this era. Large new industrial cities developed: Manchester, Liverpool, Detroit, Chicago and later on cities all over the world. The size of cities grew from Manchester 0.5 million inhabitants to over 10 million inhabitants in Chinese industrial cities Fig 2.

The current fourth era of logistical revolution manifests itself in knowledgeintensive and high-tech urban regions and corridors. It is based on a rapid extension

\footnotetext{
${ }^{1}$ Inter-urban transport and urban development; a history of logistical revolutions and Internal transport within cities and urban development are partly based on Rietveld and Bruinsma (2012).
} 


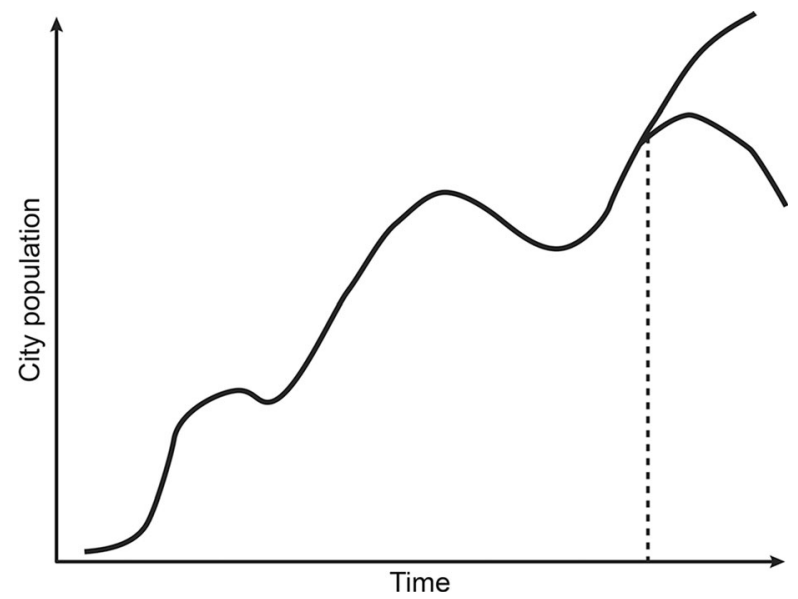

Fig. 2 Illustrative long-term trends in urban development

of motorways and air connections and on an increased capacity and speed of information processing and transmission (Karlsson et al. 2009). Keywords of this era are knowledge workers, ICT, computers, R\&D investments, out-sourcing, just-in-timesystems and customized production. Main factors behind this development have been the liberalization of international trade, international capital flows, and foreign direct investments. It is in particular in the fourth phase that the travel of persons has become the dominant factor as opposed to the transport of goods, which leads to an increasing emphasis on the need for transport at high speeds.

Karlsson et al. (2009) conclude that each revolution has been fuelled by successive technological revolutions, in particular in advances that have cut the costs of transportation of goods, people, and information. Moreover they state that the improvements have reduced transportation and communication costs and time, which have brought different parts of the world closer to each other.

Most of the literature on this subject in the regional science domain is based on the third logistical revolution. This also holds true for the new economic geography that focuses on the role of agglomeration advantages in the location of the manufacturing sector. A main result on the role of transport costs has been formulated by Krugman (1991) and is represented in Fig. 3. When transport costs are high (on the right side of the curve) agglomeration advantages are not strong enough to attract manufacturing to the core region and the manufacturing sector is just spread across the core and peripheral regions. As transport costs go down (see Table 1), a concentration tendency will occur towards the core region. The advantage of the core region is that it has a high internal market so that production is cheaper here than in the periphery. However, when transport costs decrease further, manufacturing will move to the periphery, since the share of transport costs in total production costs will decrease and the periphery is cheaper for some of the other inputs. This is the well known urban rural manufacturing shift that first took place within countries and later on occurred at the international level. An essential lesson is that reductions of transport costs can have a concentrating effect during the earlier stages of development and a deconcentration effect during the later stages. 


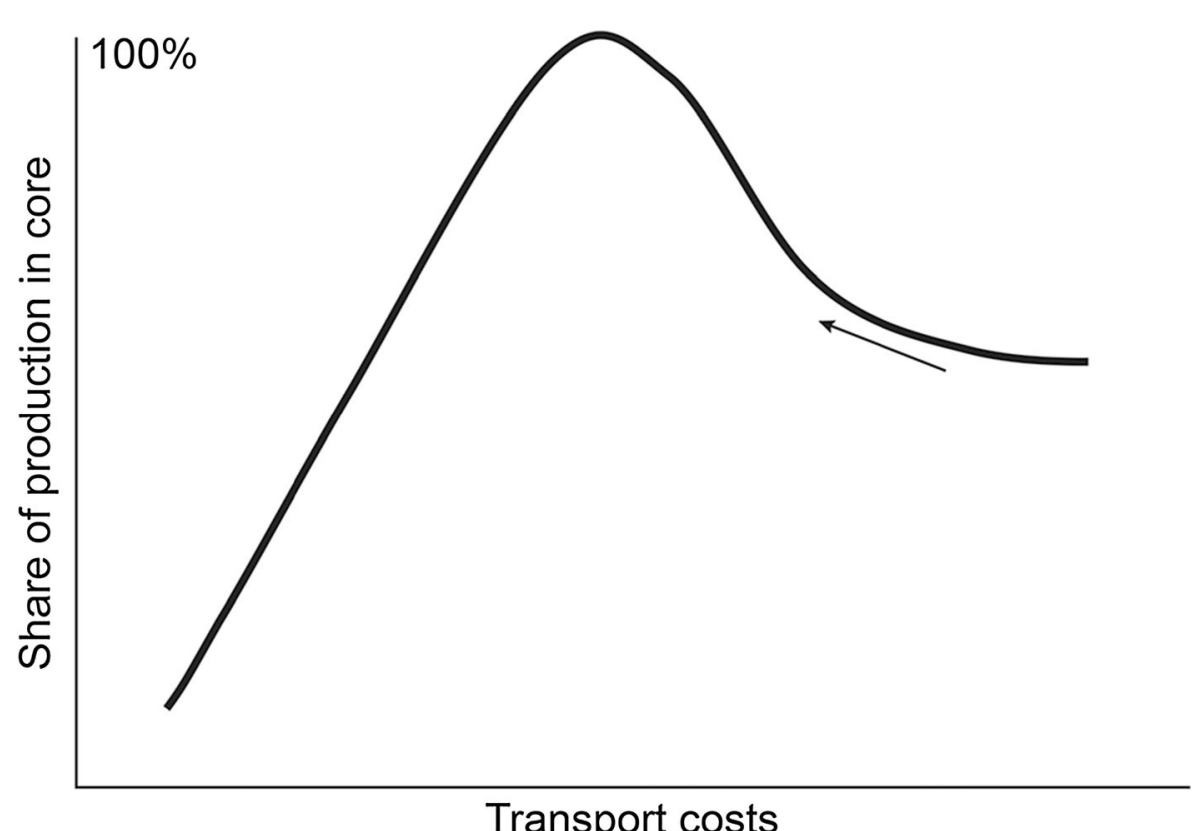

Fig 3 Illustrative concentration and deconcentration effects of changes in transport costs in a core-periphery model

An important question is of course what happens with the economic core when it loses a substantial part of its manufacturing sector. The answer is that here we arrive at the limits of this model. The increasing role of the service sector in urban and national economies is not incorporated here. And it is exactly the shift from a manufacturing driven economy to a (both business and personal) service- and knowledge-driven economy - although this also holds, to some extent, for the other transitions mentioned above - that marks the transition from the third to the fourth logistical revolution. The mechanisms of the latter will be discussed in more detail in Agglomeration advantages, transport and communications. But first we will shift the focus from the interurban to the intra-urban level.

\section{Internal Transport Within Cities and Urban Development}

In the preceding section we focused on the effects of changes in interurban transport on urban developments. In the present section we will now concentrate on the relevance of internal transport within metropolitan areas. In his interesting contribution, Clark (1958) indicates how changes in transport costs have always played a role in urban dynamics. In the nineteenth century, one of the bottlenecks observed for the larger cities was that transport of the increasing number of workers to the work places became problematic. Thus, cities remained compact and limited in size. The emergence of tramways in the second part of the nineteenth century finally enabled a process of spatial expansion of cities (Hall 1994), and this was further reinforced by the entry of the electric tram in the beginning of the 20th century, as well as by underground systems. The coming of bus and car led to a further growth of urban agglomerations, 
but now this was mainly an increase of surface area, not of population size. Gradients of density and rents started to level off. An extreme example is Los Angeles where the center-supporting role of rail was broken down and a large area with about homogeneous densities of workplaces and residences emerged.

Clark expected in 1958 a similar development for the large European agglomerations; not only sub-urbanization of residences, but also of work. However, this expectation did not come true. Examples of cities where there are still strong concentrations of work in the centers and where public transport plays a dominant role in commuting are London and New York. Although indeed a certain trend can be observed of deconcentration of work places towards the city fringes, this tendency remained limited in many cases. In addition, it appears that in those cases that jobs moved towards the fringes of the cities, this often led again to concentrations of employment. For this phenomenon, Garreau (1988) introduced the concept of edge cities. Researchers such as Henderson and Mitra (1996), Lucas and Rossi-Hansberg (2002) and Glaeser and Kahn (1993) developed new models for this purpose, in which explicit attention is paid to agglomeration advantages for firms. The center is ultimately restricted in its growth by high transport costs from the residential areas located further away. The formation of sub-centers allows the further growth of urban economies. The underlying trade-off concerns the advantages of a reduction of total transport costs of employed persons and the lower productivity that follows from the spread of economic activities in the region.

\section{Agglomeration Advantages, Transport and Communications}

Three mechanisms play a central role in agglomeration advantages: sharing, matching, and learning (Duranton and Puga 2004). The essence of sharing is that indivisible facilities with high fixed costs face high thresholds in terms of consumer demand before they become affordable for private or public suppliers. Typical examples are infrastructures such as airports, sea ports, highways, and railways. Sharing may also relate to amenities that make the life of citizens more pleasant, such as, shopping centres, museums, and hospitals. Further, sharing is relevant for human capital formation via schooling. Clearly, the sharing mechanism applies to both manufacturing and service sector activities. Matching is central in the case of heterogeneous products, services and workers. To improve the quality of matches, producers and consumers may go into intensive search activities and the costs of search clearly are lower when there are many potential matching partners in the vicinity. Finally, learning has to do with knowledge spill-overs between firms or persons that lead to an increase of productivity.

In a low-tech world, sharing, matching, and learning just depend on density of households or firms within a limited spatial range. As transport technology improves the spatial range of these mechanisms will increase. As a rule of thumb one may say that when transport becomes faster, people increase travel distances in a proportional way, so that total travel time remains more or less constant (see for example Mokhtarian, 2004; van Wee et al. 2006). The increase in travel speed thus leads to a larger number of potential sharing, matching and learning partners.

A major implication is that the traditional way of addressing urbanization economies by looking at population density in a certain demarcated urban area is superficial, since 
it ignores the costs of interaction and also the possibility of spatial interactions with destinations outside urban areas. A recent trend in research in this domain is that accessibility is used as a central concept (Melo et al. 2009), where accessibility is defined as the potential for spatial interaction that incorporates both population size of destinations and distances. One step further would be the explicit introduction of travel times in such approaches. There is indeed a strong need for making the notion of transport costs or travel times more explicit in the analysis of agglomeration advantages. Exploitation of agglomeration advantages cannot only be achieved by making cities larger or denser, but also by improving their transport systems.

The problem with many transport networks is that they tend to function rather well between nodes, but congestion is high within nodes and at the interfaces between links and nodes. City fringes are typically the place where in the real world the bottlenecks are most prominent. Thus, metropolitan areas are usually the places with lower travel speeds compared with other locations. Nevertheless, the accessibility of places within metropolitan areas is higher than elsewhere, since the low performance in terms of speed is more or less compensated by high densities. An important risk is that congestion may increase in the course of time when transport investments would lag behind, in particular since the value of time tends to increase with income, implying that the time cost of transport follows an upward trend (Gunn 2001; Rietveld and Vickerman 2004). An important consequence is that where transport costs tended to have a downward trend in the long run, this is no longer evident in the future when congestion problems are not overcome. Transport costs have declined strongly in freight transport, and also in long distance passenger transport (air and high speed rail), but this decline is not evident for short distance passenger transport in many cities.

A possible way-out may of course be the use of information and communication technology (ICT). The last decade has shown an exceptional increase in the use of internet, advanced mobile phones, and social media (Waters 2012). They have dramatically reduced the cost of communication and improved its quality, so that the 'flying carpet' metaphor is also particularly appealing here. No doubt these developments will have affected the mechanisms of sharing, matching, and learning that are the main formative forces of cities. Digital data banks showing vacant dwellings, or profiles of job seekers have strongly affected the search processes on essential urban markets such as the housing and labor market. Would this lead to major changes in the forces stimulating the formation and continued existence of cities?

An important observation is that although the last decade has witnessed an extremely rapid development in ICT applications, this is not the first time that large shocks take place in communication networks. In a similar fashion telegraph and classical telephone networks have meant revolutionary developments in the speed and costs of communication. These developments have strongly improved the efficiency of command and control activities in organizations and, hence, they have increased possibilities to run international organizations in an efficient manner. This may well have reinforced the position of a limited number of large cities as attractive locations for these large organizations (Scott 2001). Another effect has been that better communication improved the possibilities of specializing, serving larger spatial markets, and outsourcing, thus leading to a sorting of activities where some cities tend to focus on command and control, and R\&D, whereas other places specialize in manufacturing and particular services. Examples of sectors where ICT has a substantial effect on the location of 
activities are call centres and the printing industry. And also the retail sector is increasingly facing the effect of internet shops (Forman et al. 2009). A major result is that improved communication indeed leads to changes in location patterns of firms, and thus in urban systems, but the way in which this occurs is complex and cities may be affected in rather diverse manners, some strongly losing, and others gaining in opportunities.

This result probably also holds for the internet and social networks that have become so popular in the third millennium. The statements by Cairncross (2001) that distance is 'dead' or Friedman (2006) that the world is flat make a strong case that the forces that shaped cities have changed in a fundamental manner. Waters (2012) gives a nice review of the huge developments in this dynamic domain, but he emphasizes that the spatial effects are easily overestimated. For example, Barthelemy (2010) finds that geography, and hence distance, still strongly matters in social media networks, since a substantial part of interactions strongly depend on physical distances between the partners with a gravity parameter of minus 2 . Although social networks supported by the ICT driven social media no doubt have the potential to broaden the networks of people, an important part just supports and maybe reinforces the social interactions that take place via movements in the physical world. Another example is the role of languages and national preferences in the internet. Waters (2012) indicates that these play a large role. For example, while MySpace has pretty much disappeared, its rise was concentrated on the west coast of the United States, while Facebook dominated on the east coast. Thus, there are still clear signs that distance related factors are relevant.

People and firms communicate on many things. Part of the communication can easily take place via the internet or social media, and another part less so. In particular the types of contact where trust, enjoyment and emotions are crucial still seem to depend strongly on face to face contacts and this makes trips to meeting places unavoidable. Telecommunication and physical contact are imperfect substitutes. And also for the enjoyment of high quality amenities in a city, the internet cannot provide a substitute. The buzz that is typical for urban contexts (Storper and Venables 2004; Asheim and Coenen 2007; Arribas-Bel et al. 2013) and that attracts people to urban environments can only be partly substituted by the internet.

\section{Agglomeration Advantages and Transport Networks}

Agglomeration advantages imply that certain highly accessible locations become very attractive as a location for firms (and for workers since the high productivities lead to high wages). Thus, we may expect fierce competition for land and hence high land prices around these locations (see for example Fujita 1989, and Lucas and Rossi Hansberg 2002). The high land prices affect land use on these places, so that it pays to make it more intensive: higher labour/land and capital/land ratios. One of the ways to achieve this is the construction of high-rise buildings.

Since Otis invented the safe elevator in the 19th century, offices have become higher and higher. Sky-scrapers became the land marks of large metropolitan areas, such as, Chicago and New York since the 1890s (Barr 2010). Much of the discussion on changes in urban form has focused on horizontal transport (see Internal transport within cities and urban development), but it has often been overlooked that vertical 
transport must have been of equal importance. Without the development of safe and efficient elevator systems urban densities would have remained much lower. Thus, the metaphor of the 'flying carpet' applies undoubtedly to the use of the elevator in highrise buildings.

This of course depends on the capacity of elevators. The use of elevators is free and with sufficient capacity they are usually fast, which complies with the 'flying carpet' notion. However, elevator systems may also be crowded and that makes congestion theories potentially relevant. However, pricing is not introduced in this context. A key reason why, in general, the congestion problems in large office buildings are limited is that the congestion problem is internalized. The owner of the building who also uses it has an incentive to optimize the capacity of elevators given the demand of his employees. And when an office building is rented the owner will notice that the user's willingness to pay will be higher with a non congested elevator system.

There is another element in high-rise buildings that deserves mention. Not only do high-rise buildings contribute to the possibility to experience agglomeration advantages in a metropolitan area since it allows higher overall densities in cities, but they also may yield high agglomeration advantages within the buildings themselves. This holds for both residents and firms, but this holds true in the first place for internal scale advantages within a firm. For a firm the efficiency will be higher when the various divisions are not located in separate buildings - implying the use of slow and uncomfortable horizontal transport - but when related activities are concentrated in one large building. Further, large office buildings hosting more than one firm may yield similar advantages. In particular, when the high rise building hosts clients or firms among which cooperation may take place in joint projects. Large office buildings thus provide an attractive basis for matching, but also for learning and sharing. Thus, one would expect that high (= large) office buildings will yield higher rents than low office buildings. This is indeed what is found in Koster et al. (2012): high-rise buildings lead to rents that are substantially higher than those of low buildings. This is an important field of research, since it would directly demonstrate the contribution of the elevator to urbanization advantages. On the other hand, it is not so easy to disentangle the agglomeration effect from various other effects. For example, the view effect (higher floors may be more attractive and thus a higher price has to be paid) and also the status effect (having office in a really high rise building may have an additional value) have to be controlled for. And also the quality effect may play a role since the higher the building the more it pays to give it a superb but expensive entry. This is certainly a promising field of research on the flying carpet theme.

It is not possible, however, to completely separate economies owing to vertical transport in high-rise buildings from the state of horizontal transport. High-rise buildings lead to large flows of people entering these buildings and this imposes substantial requirements on horizontal transport. One direction is that sufficient parking facilities should be available at short distance implying need for multi-storey car parks. Another direction is that high-capacity public transport should be available at short distance.

This calls for a broader view on urban transport networks and their contribution to agglomeration advantages. As shown in Table 2, several ranges of distances can be distinguished where agglomeration advantages play a role. For example, for the shortest horizontal distance of approx. $500 \mathrm{~m}$ walking is the obvious choice, as is evident from many experiences. The relevance of this range can be inferred from the 
fact that universities with the many encounters between staff and students typically aim at this range of distance instead of having buildings scattered around a city. These are also the distances one may have at smaller office areas. Larger office areas and industrial parks may lead to longer distances up to say 2-3 kms. At the level of medium sized cities distances may be as long as $20 \mathrm{kms}$ and in large metropolitan areas distances may go up to $100 \mathrm{~km}$. Interurban transport will be beyond this level. For each of these ranges typical most appropriate transport modes present themselves (see Table 2). A more refined analysis of the relevant spatial ranges of matching, sharing, and learning would be most welcome to find out in which main transport mode investments are most needed.

A major step forward in the literature is provided by Rice et al. (2006) who go beyond distances and into travel times. They carry out an analysis in terms of travel time bands. They find that in the UK a doubling of the working population within a range of $30 \mathrm{~min}$ travel time increases productivity by $3.5 \%$. A doubling of the working population between 30 and 60 min leads to a productivity increase of $1.5 \%$. Between 60 and $80 \mathrm{~min}$ the increase is $0.5 \%$ and beyond $80 \mathrm{~min}$ no increase is notable. A specification of agglomeration advantages in this manner is of much help to assess the potential productivity effects of improvements in transport infrastructure. The pattern found by Rice et al. (2006) suggests that with the given transport technologies the main productivity enhancing effects of infrastructure take place in ranges up to some $20 \mathrm{kms}$, and that beyond $100 \mathrm{kms}$ the agglomeration effects are very small.

We conclude that in order to reap the potential agglomeration benefits within metropolitan areas it is essential to have adequate and tailor-made networks for distinct classes of passenger transport. At the same time it is in metropolitan areas that the costs of upgrading and new construction are highest, so that poses a considerable policy challenge. 'Flying carpets' are not yet free...

\section{Conclusion}

Transport networks have experienced growth and decline for particular transport modes during the last centuries. Cities too have their downturns and upswings, but for most cities less dramatic cycles have been observed. From a long term perspective, each

Table 2 Spatial ranges at which agglomeration economies may prevail, and the resulting relevant transport modes

\begin{tabular}{ll}
\hline Spatial range & Transport mode \\
\hline Within 1 building & Walking, elevator \\
Up to $500 \mathrm{~m}$, campus & Walking \\
Up to $3 \mathrm{~km}$ & Walking, cycling, public \\
Transport, car & \\
Up to $20 \mathrm{~km}$ (medium sized city) & Public transport, car \\
Up to $100 \mathrm{~km}$ & Car, train \\
Beyond $100 \mathrm{~km}$ & Car, HSL, air
\end{tabular}


phase of development in the logistical system during the last millennium was linked to a specific type of city that successfully made use of the logistical opportunities. That does not mean to say that cities that prospered in earlier phases completely disappeared. A tendency can be observed of an urban ratchet effect: once cities have achieved a certain level, they rarely entirely collapse given the variety of activities present that make it less vulnerable and also given the sunk costs already invested in social overhead capital. A major difference between the present stage and the preceding stages of urban development is that the developments are less dominated by freight transport; passenger transport has become often the leading part in this theme.

The main result of the long run decline in transport costs during the last century has been urban sprawl. Nevertheless the position of cities has not weakened. The reason is that metropolitan areas have just increased in spatial range, but they remain important attractors of business investments. More recently, a tendency can be discerned that central cities have become strong attractors of employment and population again. A main reason - probably more in Europe than in the USA - is the increasing valuation of the amenities, including commercial activities (in particular business services and personal services) and cultural heritage for households and firms.

Communication technology has developed extremely rapidly during the last decades. This has no doubt had a strong effect on the organization of production and the choice of its location; nevertheless cities remained remarkably robust under these changes. An important factor is no doubt that the substitution between physical transport and digital communication is smaller than is often thought. Face-to-face contacts remain essential for many types of interactions between people. And the best way to enjoy urban amenities is still to just be there.

Transport infrastructure is relevant for a wide range of distances in cities. The trend that transport becomes cheaper and faster is most probably difficult to maintain within metropolitan areas. For the effective use of agglomeration advantages a properly functioning transport system is a sine qua non. Of special relevance is the vertical dimension in transport. The use of elevators in buildings starting just before the beginning of the 20 th century will continue to have an impact during the 21 th century, if only since more and more cities and countries make ever higher buildings in order to gain prestige. So the 'flying carpet' metaphor of low cost rapid transport and communication is most telling for transport in the vertical dimension. This explains also the emergence of modern mega-cities. For horizontal transport, substantial efforts will be needed to safeguard accessibility within metropolitan areas.

Open Access This article is distributed under the terms of the Creative Commons Attribution License which permits any use, distribution, and reproduction in any medium, provided the original author(s) and the source are credited.

\section{References}

Andersson, A. E. (1986). The four logistical revolutions. Papers in Regional Science, 59(1), 1-12.

Arribas-Bel, D., Kourtit, K., \& Nijkamp, P. (2013). The socio-cultural sources of urban buzz. Environment \& Planning $C$ (forthcoming).

Asheim, B., \& Coenen, L. (2007). Face-to-face, buzz, and knowledge bases: sociospatial implications for learning, innovation, and innovation policy. Environment and Planning C: Government and Policy, 25, 655-670. 
Barr, J. (2010). Skyscrapers and the Skyline: Manhattan. Real Estate Economics, 38(3), 567-597.

Barthelemy, M. (2010). Spatial Networks. Physics Reports, 499(1-3), 1-101.

Brakman, S., Garretsen, H., \& Schramm, M. (2004). The strategic bombing of German cities during World War II and its impact on city growth. Journal of Economic Geography, 4, 201-218.

Braudel, F. (1994). A History of Civilizations. New York: A. Lane.

Brown, D. M. (1974). Introduction to Urban Economics. New York: Academic.

Cairncross, F. (2001). The death of distance: How the communications revolution is changing our lives. Boston: Harvard Business Press.

Cheshire, P. (1990). Explaining the recent performance of the European Community major urban regions. Urban Studies, 27, 311-333.

Clark, C. (1958). Transport-Maker and Breaker of Cities. Town Planning Review, 28(4), 237-250.

Crafts, N., \& Venables, A. (2001). Globalization in History: a Geographical Perspective. Cambridge: Paper prepared for the NBER conference on 'Globalization in Historical Perspective', NBER conference on 'Globalization in Historical Perspective', National Bureau of Economic Research.

Davis, D., \& Weinstein, D. (2002). Bones, Bombs, and Break Points: The Geography of Economic Activity. American Economic Review, 92, 1269-128.

Duranton, G., \& Puga, D. (2004). Micro-foundations of urban agglomeration economies. Handbook of Regional and Urban Economics, 4, 2063-2117.

Forman, C., Ghose, A., \& Goldfarb, A. (2009). Competition Between Local and Electronic Markets: How the Benefit of Buying Online Depends on Where You Live. Management Science, 55, 47-57.

Friedman, T. L. (2006). The world is flat: A brief history of the twenty-first century. London: Penguin.

Fujita, M. 1989. Urban economic theory: Land use and city size. Cambridge Univ Pr.

Garreau, D. (1988). Edge City. New York: Anchor Books.

Glaeser, E. (1999). The future of urban research: non-market interactions. Boston: Mimeo, Harvard University.

Glaeser, E., \& Kahn, M. E. (1993), Sprawl and urban growth. In Handbook of urban and regional economics. Amsterdam: North Holland.

Gunn, H. F. (2001). Spatial and temporal transferability of relationships between travel demand, trip cost and travel time. Transportation Research, 37(E), 163-189.

Hall, P. (1994). Squaring the circle: can we resolve the Clarkian paradox? Environment and Planning A, 579-594.

Henderson, V., \& Mitra, A. (1996). The new urban landscape developers and edge cities. Regional Science and Urban Economics, 26, 613-643.

Karlsson, C., Andersson, B., \& Stough, R. (2009). Entrepreneurship and development: local processes and global patterns. CESIS Electronic Working Paper Series 160.

Koks, E. (2012). To what extent do harbors influence the economic performance in a region? MSc Thesis, VU University, Amsterdam.

Koster, H.R.A., Van Ommeren, J.N., Rietveld, P. (2012). Is the sky the limit? An analysis of high-rise office buildings. Mimeo.

Krugman, P. (1991). Geography and Trade. Leuven: Leuven University Press.

Levinson, D. (2005). The Evolution of Transport Networks. In D. Hensher (Ed.), Handbook 6: Transport Strategy, Policy and Institutions (pp. 175-188). Oxford: Elsevier. Chapter 11.

Lucas, R. E., \& Rossi-Hansberg, E. (2002). On the internal structure of cities. Econometrica, 70(4), 1445-1476.

Melo, P. C., Graham, D. J., \& Noland, R. B. (2009). A meta-analysis of estimates of urban agglomeration economies. Regional Science and Urban Economics, 39(3), 332-342.

Mokhtarian, P.L., \& Chen, C. (2004). TTB or not TTB, that is the question: a review and analysis of the empirical literature on traveltime (and money) budgets, Transportation Research Part A: Policy and Practice, 643-675.

Rice, P., Venables, A. J., \& Patacchini, E. (2006). Spatial determinants of productivity: Analysis for the regions of Great Britain. Regional Science and Urban Economics, 36(6), 727-752.

Rietveld, P., \& Bruinsma, F. (1998). Is transport infrastructure effective? Transport infrastructure and accessibility: impacts on the space economy. Berlin: Springer Verlag.

Rietveld, P., \& Bruinsma, F. R. (2012). Transport and urban development. Amsterdam: VU University.

Rietveld, P., \& Vickerman, R. (2004). Transport in regional science: The death of distance is premature. Papers in Regional Science, 83(1), 229-248.

Scott, A. J. (2001). Global city-regions: trends, theory, policy. USA: Oxford University Press.

van Wee, B., Rietveld, P., \& Meurs, H. (2006). Is average daily travel time expenditure constant? In search of explanations for an increase in average travel time. Journal of Transport Geography, 14, 109-122.

Waters, N. (2012). Social networks and regional science. In M. M. Fischer \& P. Nijkamp (Eds.), Handbook in Regional Science. Berlin: Springer. 